\title{
Analysis of the need of detailed modelling for the assessment of indoor air quality in residential buildings
}

\author{
Louis Cony-Renaud-Salis ${ }^{1,}{ }^{*}$, Nouamane Belhaj ${ }^{1}$, Olivier Ramalho $^{2}$, and Marc Abadie ${ }^{1}$ \\ ${ }^{1}$ University of La Rochelle, Civil Engineering Department, 17000 La Rochelle, France \\ ${ }^{2}$ University of Paris-Est, Scientific and Technical Centre for Building (CSTB), Champs-sur-Marne, France
}

\begin{abstract}
Home represents an important part of the time spent indoors and is the emblematic place of a family need, e.g. well-being, comfort and safety. In France, health agencies provide information and raise the awareness of the public on health risks and on factors likely to affect the quality of indoor air. However, indoor air quality remains difficult to assess for health investigators. A solution would be to resort to field measurements, but they are expensive and hard to apply to a large-scale population when considering the numerous pollutants found indoors. Therefore, numerical simulation represents a good alternative when accurate and realistic input data are used. We already designed such a model of a dwelling prototype using a type 98 coupling procedure between CONTAM (airflow rates and pollutants concentration determination) and TRNSYS (thermal and moisture calculation). We paid a lot of attention to the details that we thought were important: dwelling multi-zonal representation, envelope airtightness, ventilation system elements (pressure driven inlet and outlet, ducts, fan characteristics), presence of furniture, people activity and location... Nevertheless, the design of this simulation requires a very specific care. This very last point naturally induces a debate: is it necessary to design the simulation to be as accurate and realistic as it actually is, or will a simpler model provide similar results? In this study, we aim to answer that question by evaluating the sensitivity of the ULR-IAQ multipollutant index, defined in a previous study, to different levels of modelling complexity.
\end{abstract}

\section{Introduction}

Assessment of Indoor Air Quality (IAQ) is nowadays a main issue. Indeed, human beings spend in average $80 \%$ of their time indoors with $70 \%$ at home. There are actually many research studies on the development of sensors or depolluting materials to improve IAQ [1-3]. To be effective, these fields of research require relevant knowledge of actual air quality in residential buildings. To obtain such data there are two main ways to proceed: going through a measurement campaign or using a numerical simulation.

Performing measurements in laboratory test chambers is the common way of improving our knowledge on indoor sources. Although it proves to be very useful to study specific elements individually related to pollutant physics (pollutant emission rate from material, sorption and deposition rate from/to material, pollutant distribution in rooms...), it is not so relevant when it comes to a whole dwelling because of the complexity of real indoor spaces in terms of geometry, material, occupant behaviour...

A large scale dwelling measurement campaign provides very useful information but it is expensive, timeconsuming and there are still technological limitations to provide continuous measurement of concentration for all pollutants. Most of exposure campaign studies only provide one or two weeks averaged concentration with no detail on the variability of the pollutant concentration levels. Furthermore, when investigating occupied dwellings, it is not possible to have any control on the way people are living in the dwelling. Therefore, the interaction between occupant specific behaviour and IAQ is difficult to anticipate

Numerical simulation allows to detail the evaluation of the cumulative effects of data collected by laboratory or in-situ measurements. If input data are sufficiently relevant, it is possible to build a simulation that provides consistent results and allows a full control over pollution scenarios. We designed a multi-zone simulation to be as accurate and realistic as possible thanks to a type 98 coupling procedure between CONTAM and TRNSYS softwares as well as statistical data created out of PANDORA indoor emission rates database [4]. Even if it still requires further validation, this approach provides results that are partially in agreement with those obtained by the national survey conducted in 2005 by the French IAQ observatory [5]. Considering the number of parameters and physical phenomena that are taken into account, this simulation reaches a certain level of complexity that makes it time-consuming to set up. The dedicated attention and expertise that are needed before running the simulation can be subject to debate regarding the accuracy of results relevant to the IAQ assessment.

\footnotetext{
${ }^{*}$ Corresponding author: louis.cony-renaud-salis@univ-lr.fr
} 
This study aims to evaluate the level of complexity required in the simulation in relation to the quantification of IAQ pollutants. In this paper, we aim to answer two questions:

- Is there a need to simulate the real variation of concentration within each room? On the other hand, could the model be simplified to only considerer one or two zones?

- What is the benefit of fully coupled simulation compared with simple pressure-driven calculations with imposed temperatures?

The analysis will be performed by simulating the IAQ of a prototype two-floor dwelling. The first section of this paper aims at describing the modelling methodology and the simulated cases. Then, the results obtained will be presented for the different cases in terms of airflow rates, pollutant concentration levels and IAQ multipollutant indices. Finally, we will discuss the various levels of complexity.

\section{Methods}

\subsection{Building design and location}

The prototype building (Figure 1) is similar to the detached dwelling used in the QUAD-BBC project [6] i.e. walls, windows, ceilings and floors have the same material composition (thermal and humidity properties) and heating temperature set points and standard scenario were also selected according to this study. There are currently no scientific studies describing the quantity of furniture in a typical dwelling. Therefore, arbitrary choices had to be made. Everyday objects with available data on indoor emission rate of volatile organic compounds (VOC) or particulate matter (PM) were also added in the house such as books, shoes, computers, TV monitor....

The ventilation and airtightness sizing were conducted as described in French standards for ventilation (French decree of 03/24/1982 defining standard airflow rates for dwellings). The fan provides either high or low airflow rates $\left(180 / 105 \mathrm{~m}^{3} / \mathrm{h}\right)$. High airflow rate is activated only 30 minutes during cooking time (at 12:00 and 19:30). Three ventilation systems commonly encountered in French housing have been considered i.e. natural ventilation (vertical duct), self-regulated exhaust ventilation and balanced ventilation. Envelope airtightness is assumed homogeneous and corresponds to an envelope permeability index of $\mathrm{Q}_{4 \mathrm{~Pa}}=0.6 \mathrm{~m}^{3} /\left(\mathrm{h} . \mathrm{m}^{2}\right)\left(\mathrm{n}_{50}\right.$ $=1.2$ ach at $4 \mathrm{~Pa}$ indoor to outdoor pressure difference).

\subsection{Simulation procedure and input data}

The energy and airflow modelling of the house was done using the type 98 coupling process between CONTAM and TRNSYS softwares. As described in Figure 2, zone temperatures and humidities are evaluated in TRNSYS and forwarded to CONTAM to calculate airflow rates between rooms, with the outdoor environment and the pollutant concentration in the different rooms. Multizone airflow rates are looped on TRNSYS inputs to update multizone airflow and calculate back energy and hygrothermal properties of the air in the different zones. Pollutant concentration is finally used to estimate IAQ.

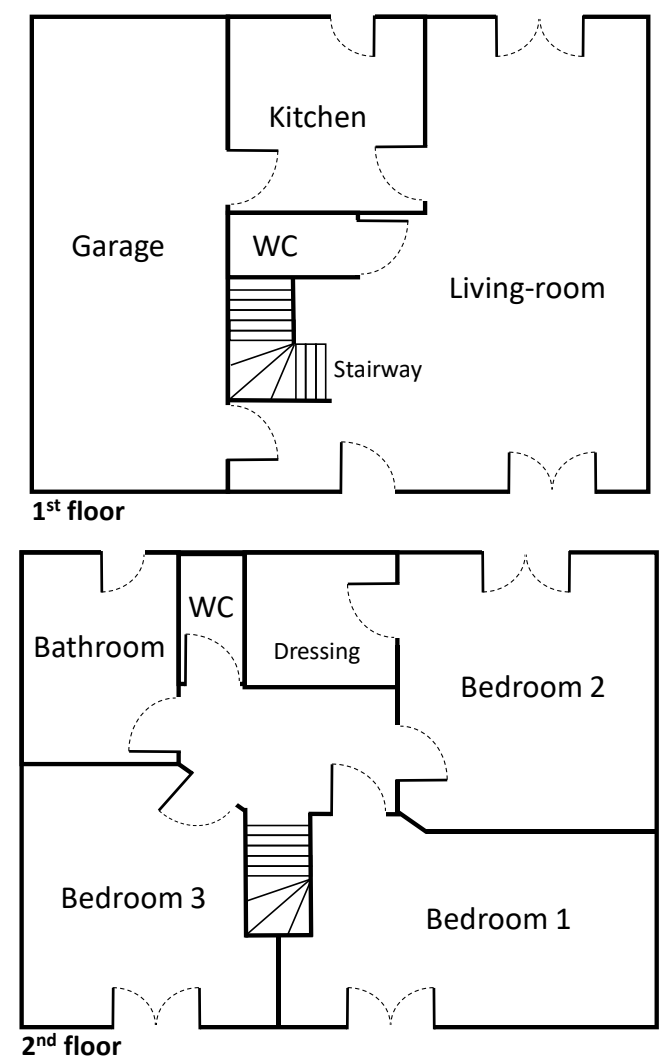

Fig. 1. Building design.

Heat (lighting, computer, cooking) and moisture (washing dishes, showering, doing laundry or drying machines) generations are taken from [7-11].

Outdoor pollution was collected from the local air quality monitoring station available which provide continuous outdoor $\mathrm{SO}_{2}, \mathrm{NO}_{2}, \mathrm{O}_{3}$ and $\mathrm{PM}_{10}$ hourly concentration levels for La Rochelle city [12]. Indoor emission levels (both transient and non-transient) were defined as the distribution statistics from PANDORA (a data analysis tool was created in the purpose of this work) indoor emissions database filtered by pollutant and material [4]. The simulated house is assumed to be representative of the average French building stock so that, after a few sampling simulations, the authors decided to set each indoor emission level to the 25th percentile of PANDORA data, in this study.

Construction elements are only considered as sources and the VOC emissions of the coating surfaces for floor, walls and ceiling have been accounted. No pollutant sorption effect has been considered in the present simulations. 


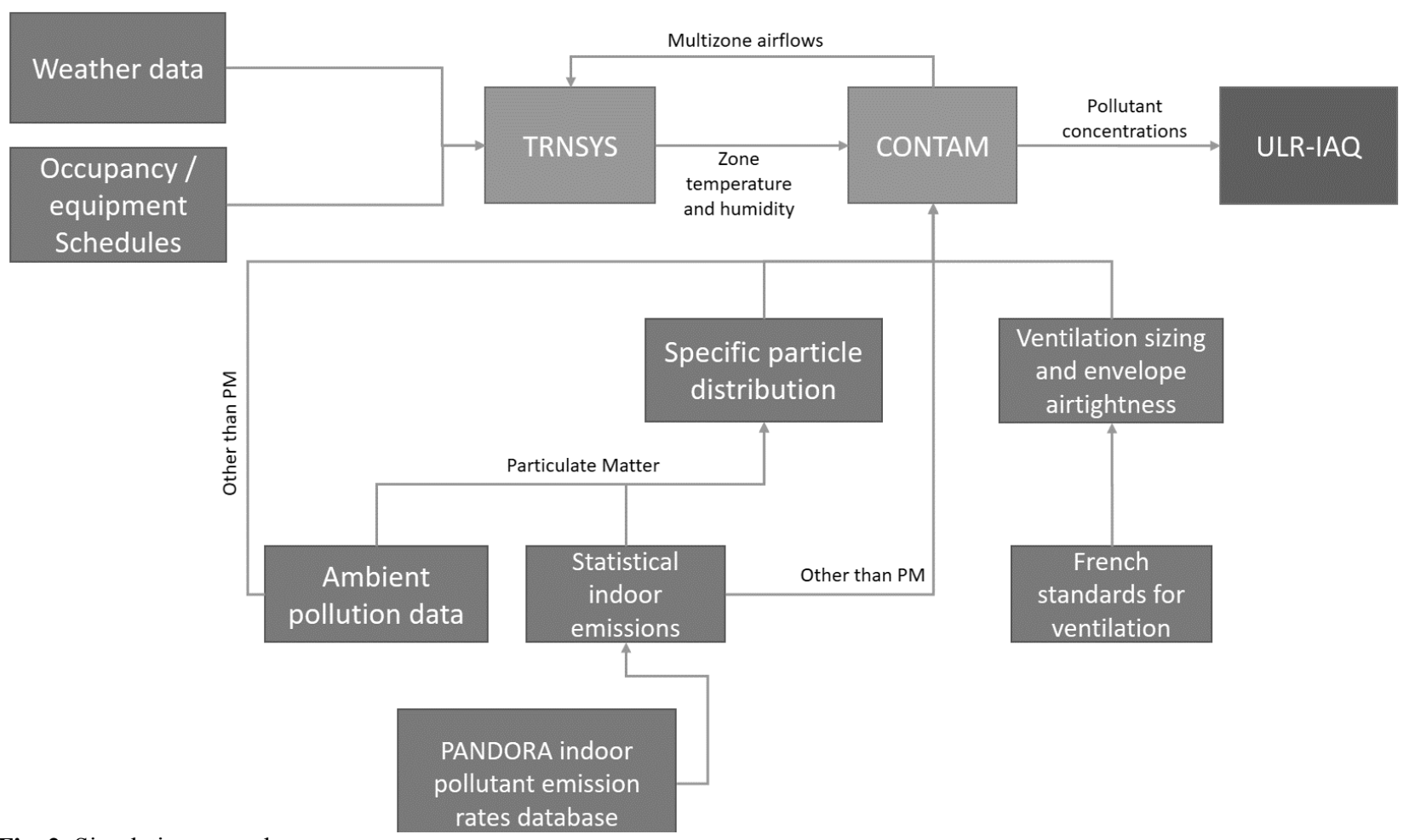

Fig. 2. Simulation procedure.

Particulate matter (PM) were not considered only as $\mathrm{PM}_{2.5}$ and $\mathrm{PM}_{10} . \mathrm{PM}_{10}$ was divided into 20 particle size bins in order to account for particle size dependent process (sources and deposition). Indoor particle emission size distribution was determined from PANDORA for each type of emission and outdoor particle size distribution in urban environment was found by Klejnowski [13]. Particle deposition was calculated according to [14].

Finally, transient pollutant concentrations are used to calculate University of La Rochelle Indoor Air Quality Index (ULR-IAQ). The formula is the following:

$$
I_{U L R-I A Q}=\max \left(\frac{10\left(C_{i n d, i}-I A G V_{L T, i}\right)}{I A G V_{S T, i}-I A G V_{L T, i}}\right)
$$

Where $I A G V_{L T, i}$ is the indoor air guideline value for longterm exposure (usually 1 year) to a pollutant, $I A G V_{S T, i}$ is the indoor air guideline value for short-term exposure (shortest available) and $C_{i n d, i}$ is the indoor concentration of pollutant i.e. if $C_{i n d, i}>I A G V_{S T, i}$ then $C_{i n d, i}=I A G V_{S T, i}$ and if $C_{\text {ind }, i}<I A G V_{L T, i}$ then $C_{\text {ind }, i}=I A G V_{L T, i}[15]$.

In order to compare 4 level of complexity, a copy of each simulation is made but is not coupled with TRNSYS. To create a monozone simulation (one floor = one zone), a copy is made from the non-coupled (NC) simulation and all indoor walls are removed, then the project is coupled to TRNSYS. Finally a last copy of the mono simulation is made but is not coupled to TRNSYS, this is the monozone non-coupled (mono NC) simulation. This procedure enables to minimize unintended setup differences such as pollutants source emissions and controls, ventilation and occupancy schedules...

In all simulated scenarios, windows are maintained closed and an exhausting kitchen hood $\left(400 \mathrm{~m}^{3} / \mathrm{h}\right)$ is used at cooking times. The smoker scenario consists in smoking two cigarettes $(10 \mathrm{~min} /$ cigarette) in the living room at 18:30 and 21:00 every day. The simulation is ran with a time step of 5 seconds over one winter week. In each case, we will compare airflow rates, pollutant concentrations and ULR-IAQ values; relatively to the multizone-coupled simulation, which is considered as the reference. Indeed we made the assumption that multizone coupled simulation is more accurate since it gathers the finest physical description among all simulations. In this paper, we call Standard Deviation (SD) the relative difference in absolute terms between reference and compared results.

\section{Results and discussion}

\subsection{Airflow rates}

\subsubsection{Mechanical ventilation}

Figure 3 presents the airflow rates for the kitchen, the bathroom and the stairway determined with the balanced ventilation system. We chose to plot only the airflow rates that were possible to compare in each situation i.e. between the multizone and monozone configurations. Note that the results for the self-regulated exhaust ventilation system are very similar; therefore, they are not presented in this paper. 
Outlets airflow rates behave exactly as it should. The flow is constant and increases when high airflow rate is activated. Stairway airflow is more fluctuating because it is a wide-open space that is very sensitive to temperature variation e.g. opening and closing of bedrooms doors at 7:00 and 22:00 (set point temperature is different between rooms and hall); or heat attributed to inhabitant activity (light or human body heat) after 18:00 (time at which people return home in these scenarios).

Figure 4 and 5 are showing airflow rates SD respectively for outlets and stairway with Balanced ventilation.

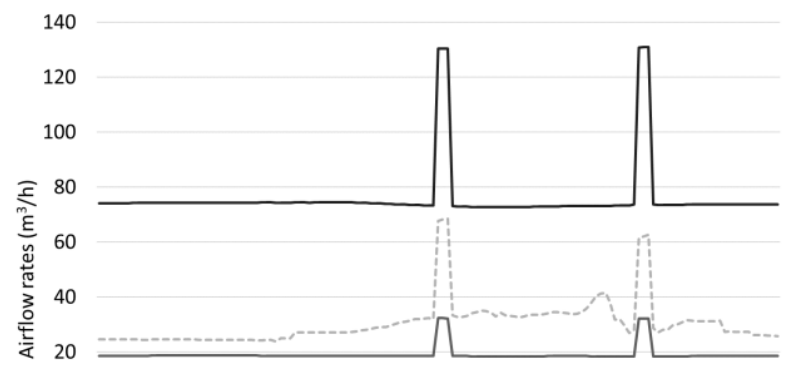

$$
\begin{aligned}
& 0
\end{aligned}
$$

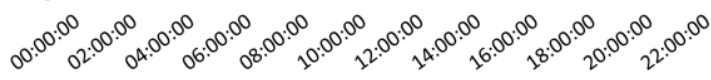

$$
\begin{aligned}
& \text {---Stairway -Bathroom —Kitchen }
\end{aligned}
$$

Fig. 3. Balanced ventilation airflow rates multizone-coupled simulation.

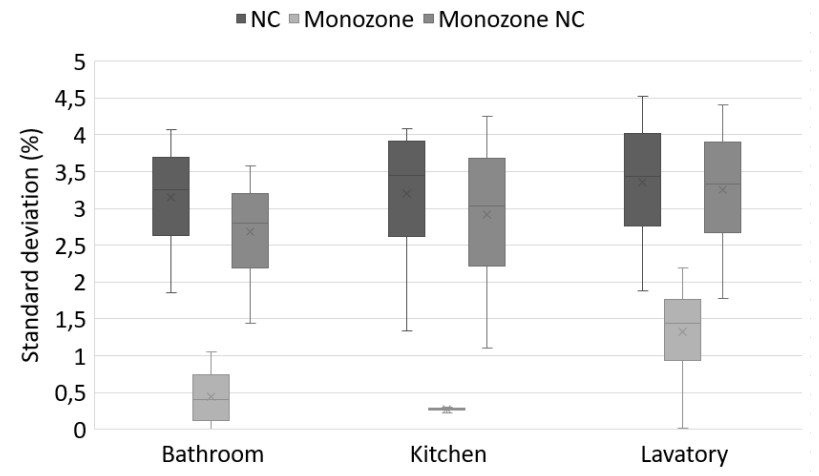

Fig. 4. Balanced ventilation airflow rates standard deviation of outlets.

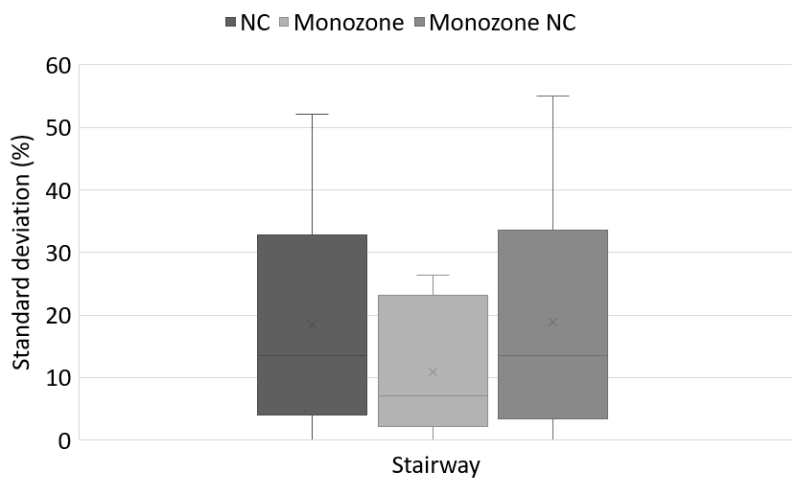

Fig. 5. Balanced ventilation airflow rates standard deviation of stairway.

Outlets airflow rates have a very small standard deviation $<4.5 \%$ in worst case and $<2.5 \%$ for monozone-coupled simulation. This small standard deviation is mainly due to the mechanical ventilation installed in ducts that was precisely sized to pump out these flows. Stairway airflow rates have a high standard deviation at some precise moments: $\approx 54 \%$ for $\mathrm{NC}$ simulations and $27 \%$ for monozone-coupled simulation. Monozone simulations cannot account for opening and closing of bedrooms doors and non-coupled simulations is not able to detect any temperature changes. Nevertheless average standard deviation is acceptable in terms of accuracy $(<15 \%)$.

In each case, the monozone-coupled simulation gives more accurate results than other non-coupled simulations. This tends to prove the importance of accounting temperature behaviour to model airflow rates in a simulation.

\subsubsection{Natural ventilation}

Figure 6 presents natural ventilation airflow rates. Due to the absence of mechanical ventilation, we notice that flows are reversing directions when the kitchen hood is activated. There is also a bigger fluctuation because flows are more sensitive to outdoor conditions. Figure 7 presents airflow rates standard deviation for outlets and stairway with natural ventilation.

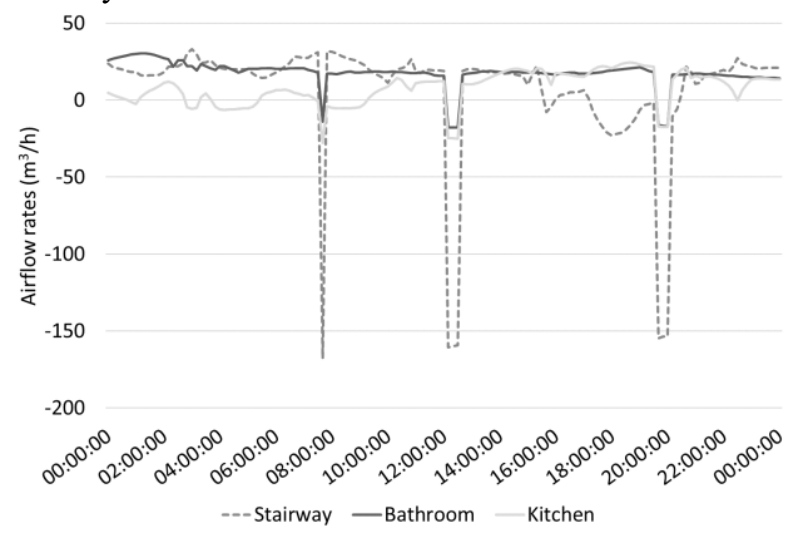

Fig. 6. Natural ventilation airflow rates multizone-coupled simulation.

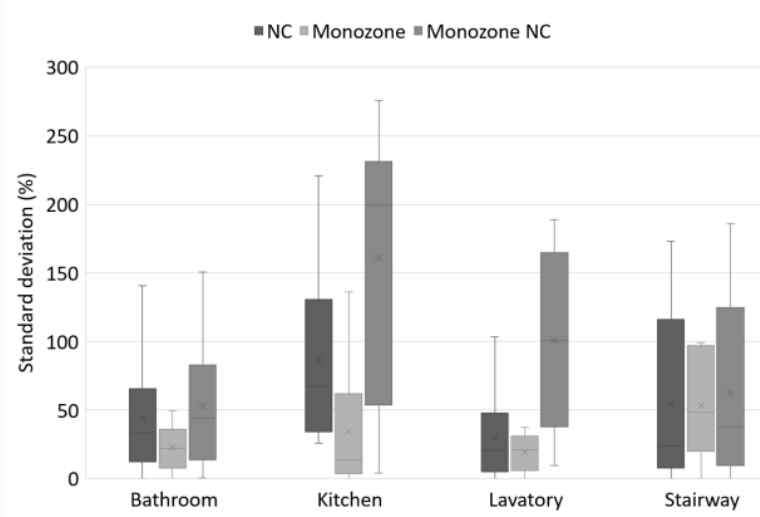

Fig. 7. Natural ventilation airflow rates standard deviation.

Airflow rates standard deviations are considerably higher with natural ventilation in all situations: $[47 \% ; 135 \%]^{\mathrm{a}}$ for

a [Average ; Maximum] 
NC, $[26 \% ; 88 \%]$ for mono and $[67 \% ; 189 \%$ ] for mono NC. The model accuracy is too low to assess airflow rates properly in a building without using a multizone-coupled simulation. This time there is no mechanical ventilation, therefore air is moving through the dwelling by means of thermal buoyancy and wind pressure effects. Both geometry and precise thermal description affect simulation results. Data obtained with coupled simulation is again more accurate than NC simulations.

\subsection{Pollutants concentrations}

\subsubsection{Transient pollutants concentrations}

Figure 8 presents transient exposure indoor concentrations (the concentration one person is exposed to when going in different rooms of the house) of formaldehyde, acrolein, $\mathrm{PM}_{2.5}$, benzene, toluene and Trichloroethylene during weekday and ran on a classical scenario with balanced ventilation. Figure 9 presents same data with a smoker scenario that consists in smoking 2 cigarettes during the evening, the first one at 18:00 and the second one at 21:10.

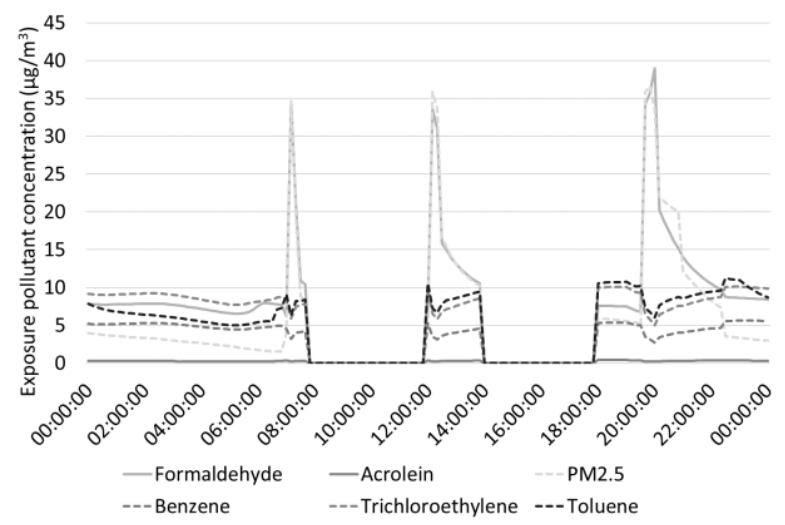

Fig. 8. Transient pollutants concentration during exposure period for balanced ventilation multizone-coupled simulation in weekday, classical scenario.

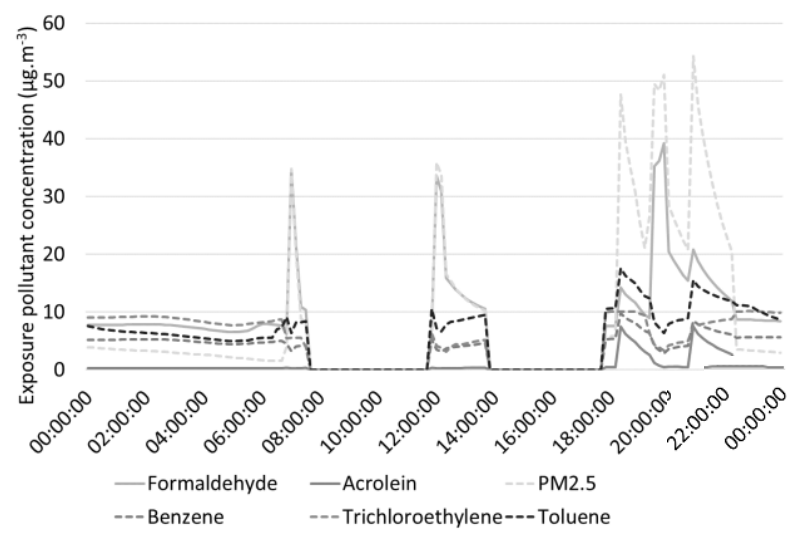

Fig. 9. Transient pollutants concentration during exposure period for balanced ventilation multizone-coupled simulation in weekday, smoker scenario.
On Figure 8 we notice peaks of $\mathrm{PM}_{2.5}$ and Formaldehyde at cooking time (7:00, 12:00 and 19:40). On the contrary, other pollutants concentration decrease because cooking activities are not emitting it and they are pumped out by the kitchen hood. On Figure 9 we notice the same peaks during cooking time, with also 2 peaks of Formaldehyde, Acrolein, PM2.5, benzene and toluene at times corresponding to smoking activities. Results obtained are in good agreement with what could be expected with such scenarios. Even if there is a difference of pollutant level due to the value of airflow rate, for all ventilation systems, pollutants have the same behaviour because sources are identical. Therefore, only balanced transient concentrations are presented in this paper. Except from benzene, which is overestimated, levels of pollution are in agreement with what was previously measured in national French measurement survey.

\subsubsection{Standard deviations}

From Figures 10 to 12 , Standard deviations of pollutant concentrations are presented for balanced ventilation (Figure 10), single flow exhaust ventilation (Figure 11) and natural ventilation (Figure 12). In each figure, both classical and smoker scenarios are compared.

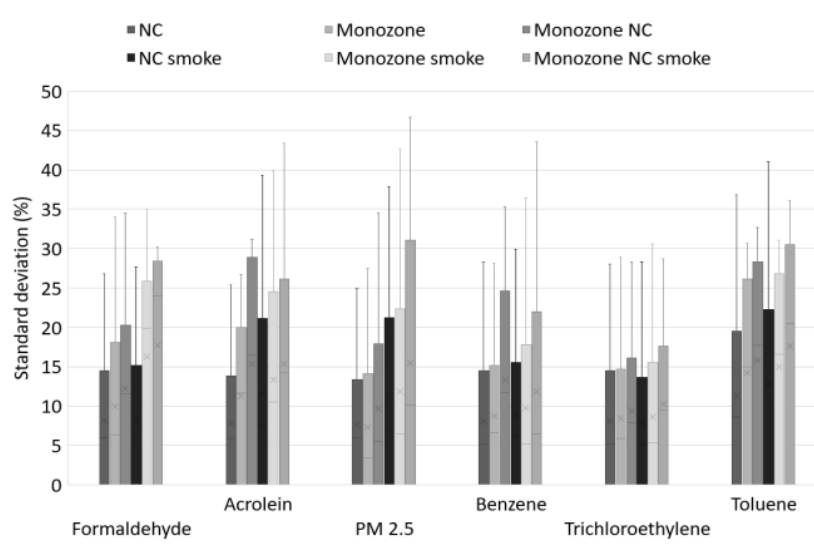

Fig. 10. Standard deviations of pollutants concentrations with balanced ventilation, classical and smoker scenarios.

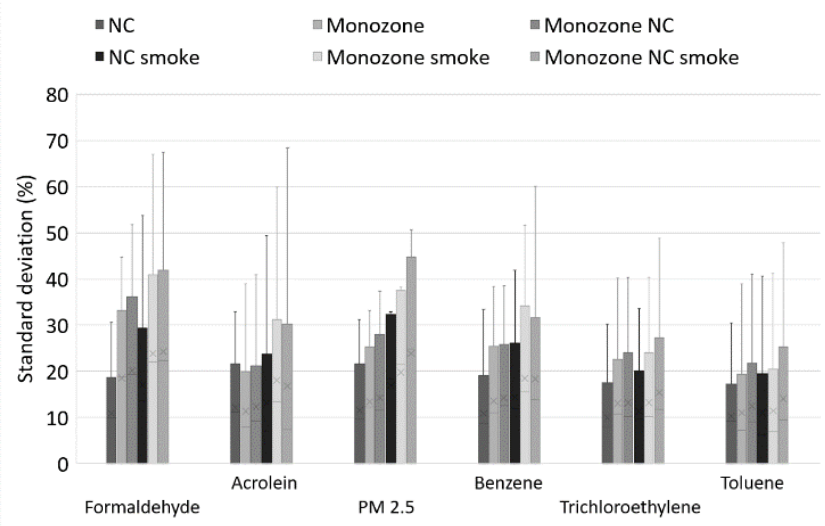

Fig. 11. Standard deviations of pollutants concentrations with single-flow ventilation, classical and smoker scenarios. 
In each case multizone NC simulation is more accurate than other monozone simulations. Monozone simulations consider one level as a uniform zone, therefore a pollutant that should be emitted only in one place in multizone will be equally emitted in the whole level in monozone, which naturally reduces accuracy. For example, chemical species emitted during cooking activities should be located in the kitchen and directly pumped out outdoor without spreading to the other rooms. If the simulation is monozone, the species will be homogeneously distributed in all rooms.

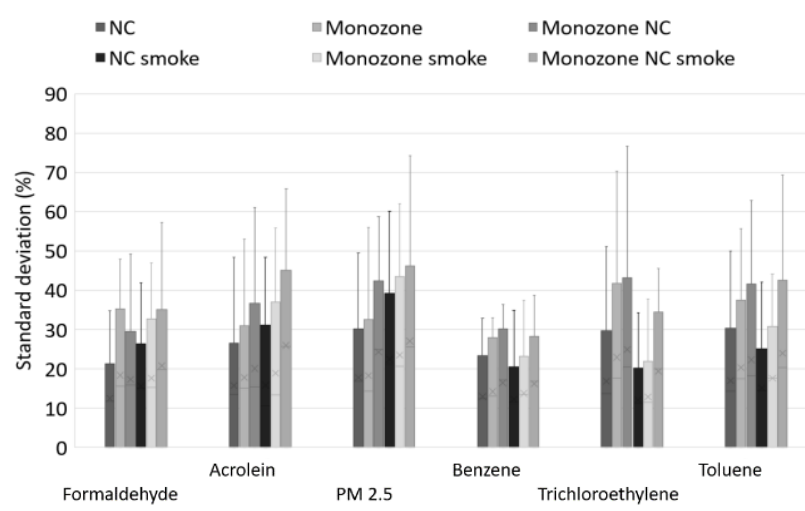

Fig. 12. Standard deviations of pollutants concentrations with natural ventilation, classical and smoker scenarios.

While comparing different scenarios, we see no clear correlation between accuracy and complexity of scenario. Indeed, there is no significant difference between classical and smoker scenario in each case.

If we compare accuracy of the various ventilation systems, the more we rely on mechanical ventilation, the more accuracy increases. Average standard deviation goes from $20 \%$ for natural ventilation to $14 \%$ in single flow ventilation and $11 \%$ in balanced ventilation.

\subsection{ULR-IAQ values}

ULR IAQ is used as an index to assess indoor air quality in this study. Since the scenarios describe the occupation of typical active people, the dwelling is empty during working period. In this paper, we focus only on what happens in the house. Therefore, the exposure concentration is considered only at occupational time. Table 1 gathers ULR-IAQ values and standard deviations and identifies the pollutant of higher sub-index value as per equation (1).

A validation study still needs to be conducted to compare the simulation results with real measurements. Yet, the results obtained so far are promising. A balanced ventilation is more efficient than single flow, and single flow is better than natural ventilation. Smoking in indoor environment worsens IAQ. The less a room is ventilated, the more a source of indoor pollution can affect IAQ.
As expected from pollutant concentration results, we notice that multizone simulations are always more accurate than monozones.

Table 1. ULR IAQ values, standard deviation and top pollutants.

\begin{tabular}{|c|c|c|c|c|}
\hline Scenario & $\begin{array}{c}\text { Simulation } \\
\text { type }\end{array}$ & $\begin{array}{l}\text { ULR } \\
\text { IAQ }\end{array}$ & $\begin{array}{l}\text { Standard } \\
\text { deviation }\end{array}$ & $\begin{array}{c}\text { Top } \\
\text { pollutant }\end{array}$ \\
\hline \multirow{4}{*}{$\begin{array}{l}\text { Balanced } \\
\text { Classical }\end{array}$} & $\begin{array}{l}\text { Multizone } \\
\text { coupled }\end{array}$ & 1.0 & - & \multirow{4}{*}{ Benzene } \\
\hline & $\begin{array}{c}\text { Multizone } \\
\text { non-coupled }\end{array}$ & 1.1 & $17 \%$ & \\
\hline & $\begin{array}{c}\text { Monozone } \\
\text { coupled }\end{array}$ & 1.2 & $19 \%$ & \\
\hline & $\begin{array}{c}\text { Monozone } \\
\text { non-coupled }\end{array}$ & 1.3 & $37 \%$ & \\
\hline \multirow{4}{*}{$\begin{array}{c}\text { Balanced } \\
\text { smoke }\end{array}$} & $\begin{array}{c}\text { Multizone } \\
\text { coupled }\end{array}$ & 1.2 & - & \multirow{4}{*}{$\mathrm{PM}_{2.5}$} \\
\hline & $\begin{array}{c}\text { Multizone } \\
\text { non-coupled }\end{array}$ & 1.8 & $54 \%$ & \\
\hline & $\begin{array}{l}\text { Monozone } \\
\text { coupled }\end{array}$ & 2.0 & $64 \%$ & \\
\hline & $\begin{array}{c}\text { Monozone } \\
\text { non-coupled }\end{array}$ & 2.2 & $81 \%$ & \\
\hline \multirow{4}{*}{$\begin{array}{l}\text { Single } \\
\text { Flow } \\
\text { classical }\end{array}$} & $\begin{array}{l}\text { Multizone } \\
\text { coupled }\end{array}$ & 1.1 & - & \multirow{4}{*}{ Benzene } \\
\hline & $\begin{array}{l}\text { Multizone } \\
\text { non-coupled }\end{array}$ & 2.0 & $82 \%$ & \\
\hline & $\begin{array}{c}\text { Monozone } \\
\text { coupled }\end{array}$ & 2.1 & $92 \%$ & \\
\hline & $\begin{array}{l}\text { Monozone } \\
\text { non-coupled }\end{array}$ & 2.1 & $92 \%$ & \\
\hline \multirow{4}{*}{$\begin{array}{l}\text { Single } \\
\text { Flow } \\
\text { smoke }\end{array}$} & $\begin{array}{c}\text { Multizone } \\
\text { coupled }\end{array}$ & 3.2 & - & \multirow{4}{*}{$\mathrm{PM}_{2.5}$} \\
\hline & $\begin{array}{l}\text { Multizone } \\
\text { non-coupled }\end{array}$ & 5.2 & $63 \%$ & \\
\hline & $\begin{array}{c}\text { Monozone } \\
\text { coupled }\end{array}$ & 5.9 & $85 \%$ & \\
\hline & $\begin{array}{c}\text { Monozone } \\
\text { non-coupled }\end{array}$ & 6.1 & $90 \%$ & \\
\hline \multirow{4}{*}{$\begin{array}{c}\text { Natural } \\
\text { ventilation } \\
\text { classical }\end{array}$} & $\begin{array}{l}\text { Multizone } \\
\text { coupled }\end{array}$ & 1.5 & - & \multirow{4}{*}{ Benzene } \\
\hline & $\begin{array}{c}\text { Multizone } \\
\text { non-coupled }\end{array}$ & 3.9 & $157 \%$ & \\
\hline & $\begin{array}{c}\text { Monozone } \\
\text { coupled }\end{array}$ & 3.9 & $160 \%$ & \\
\hline & $\begin{array}{c}\text { Monozone } \\
\text { non-coupled }\end{array}$ & 4.2 & $176 \%$ & \\
\hline \multirow{4}{*}{$\begin{array}{c}\text { Natural } \\
\text { ventilation } \\
\text { smoke }\end{array}$} & $\begin{array}{l}\text { Multizone } \\
\text { coupled }\end{array}$ & 4.0 & - & \multirow{4}{*}{$\mathrm{PM}_{2.5}$} \\
\hline & $\begin{array}{c}\text { Multizone } \\
\text { non-coupled }\end{array}$ & 7.2 & $78 \%$ & \\
\hline & $\begin{array}{c}\text { Monozone } \\
\text { coupled }\end{array}$ & 8.1 & $102 \%$ & \\
\hline & $\begin{array}{c}\text { Monozone } \\
\text { non-coupled }\end{array}$ & 8.4 & $109 \%$ & \\
\hline
\end{tabular}

Average standard deviation of index is $45 \%$ for balanced ventilation; $84 \%$ for single flow ventilation and $130 \%$ for natural ventilation. Index standard deviations are too high 
to provide a relevant analysis tool. Index standard deviations are about 5 times higher than concentrations standard deviations. Considering the shape of ULR IAQ formula, this dilatation is logical. Indeed, the index standard deviation is calculated as follows:

$$
S D=\left|\frac{I_{U L R-I A Q, \text { ref }^{-I}} I_{U L R-I A Q, \text { compare }}}{I_{U L R-I A Q, \text { ref }}}\right|
$$

Which can be developed and simplified into:

$$
S D=\frac{x C_{\text {ind,ref }}}{C_{\text {ind,ref }}-I A G V_{L T}}
$$

Where $S D$ is the index standard deviation and $x$ is the concentration standard deviation. Since $I_{U L R-I A Q, \text { ref }}$ is $>0$; the ratio $\frac{C_{\text {ind }}}{C_{\text {ind }}-I A G V_{L T}}$ is always $>1$, which means that index standard deviation will always be higher than concentration standard deviation. It proves that an approximate concentration cannot be used to calculate ULR IAQ value. Even if simplified simulations provide an acceptable trend of pollutants behaviour, it will induce a high uncertainty in the ULR IAQ index.

\section{Conclusion}

In order to perform the global assessment of IAQ in a dwelling, we previously designed a complex numerical simulation based on a type 98 coupling procedure between CONTAM and TRNSYS softwares. To be as realistic as possible, this simulation reached a certain level of complexity; this paper aims to compare accuracy of a complex simulation versus more simplified ones (Noncoupled, Monozone-coupled, and Monozone noncoupled).

For balanced and single flow ventilations, the accuracy of airflow rates is very good inside ducts $(<4.5 \%)$ but it highly decreases in stairway. Any level of complexity is acceptable but monozone simulations do not provide inter-zone airflow rates. Natural ventilation relies on natural pressure and temperature variations and thus accuracy is highly affected by complexity. Airflow rates are globally more accurate with monozone coupled simulations rather than other Non-coupled simulations.

Dynamic exposure concentration of pollutants is correct for a Multizone non-coupled simulation with mechanical ventilation. Similar trends are visible, other monozones simulations are less accurate. Standard deviation is higher in natural ventilation; multizone non-coupled simulation is not accurate enough to describe finely indoor concentrations, but it can be used to visualize how concentration is evolving while reducing calculation time from $\approx 180$ s (multizone coupled) to $\approx 35$ s (monozone NC).
ULR-IAQ is highly affected by the various levels of complexity, even in balanced multizone non-coupled simulation. Any concentration standard deviation is amplified by the index formula. An approximate simulation cannot be used to assess properly ULR-IAQ.

\section{Acknowledgement}

The authors want to thank the Nouvelle Aquitaine Region (CPER 2015-2020 "Bâtiment Durable") and Health Agency (former ARS-Poitou-Charentes) for funding this research project.

\section{References}

1. T. Salthammer, F. Fuhrmann, Env., Sci. \& Tech. 41, 18 (2007)

2. F. Thevenet, O. Debono, M. Rizk, F. Caron, M. Verriele, N. Locoge, Build. and Env., 137, 138-146 (2018)

3. J. Gunschera, J.R. Andersen, N. Schulz, T. Salthammer, Chem., 75, 4 (2009)

4. M.O. Abadie, P. Blondeau. HVAC\&R Res. 17 ,4, 602-613 (2011)

5. S. Kirchner, M. Derbez, C. Duboudin, P. Elias, A. Gregoire, J.P. Lucas, N. Pasquier, O. Ramalho, N. Weiss, Indoor Air (2008)

6. $Q U A D-B B C$ (2012)

7. IEA, Report Annex XIV, 1. (1991)

8. L.G. Mansson. IEA ECBCS Annex 27 Evaluation and Demonstration of Domestic Ven-tilation Systems Simplified Tools Handbook (2001)

9. J. Ribéron, J.R. Millet, CSTB notebook $n^{\circ} 2526,323$ (1991)

10. S. Pallin, P. Johansson, C.E. Hagentoft, Building Simulation 2011, 12th (IBPSA) (2011)

11. M. Schell, D. Smith, ASHRAE journal (2002)

12. ATMO. http://www.atmonouvelleaquitaine.org/donnees/telecharger (2018)

13. K. Klejnowski, A. Krasa, W. Rogula-Kozlowska, B. Blaszczak. The Sci. World Jour. (2013)

14. A.C.K. Lai and W.W. Nazaroff. J. Aer. Sci., 31,463476 (2000)

15. L. Cony-Renaud-Salis, O. Ramalho, M.O. Abadie, AIVC 2017 (2017) 